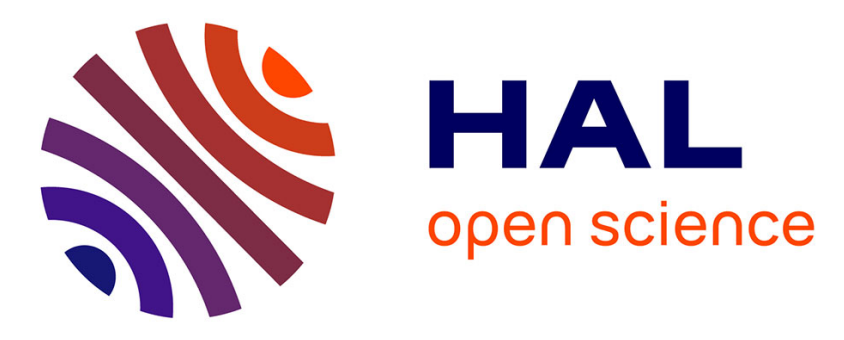

\title{
Cyclic (Alkyl)(amino)carbene Ligands Enable Cu-Catalyzed Markovnikov Protoboration and Protosilylation of Terminal Alkynes: A Versatile Portal to Functionalized Alkenes**
}

Yang Gao, Sima Yazdani, Aaron Kendrick, Glen Junor, Taeho Kang, Douglas Grotjahn, Guy Bertrand, Rodolphe Jazzar, Keary Engle

\section{To cite this version:}

Yang Gao, Sima Yazdani, Aaron Kendrick, Glen Junor, Taeho Kang, et al.. Cyclic (Alkyl)(amino)carbene Ligands Enable Cu-Catalyzed Markovnikov Protoboration and Protosilylation of Terminal Alkynes: A Versatile Portal to Functionalized Alkenes**. Angewandte Chemie International Edition, 2021, 60 (36), pp.19871-19878. 10.1002/anie.202106107 . hal-03349897

\section{HAL Id: hal-03349897 https://hal.science/hal-03349897}

Submitted on 5 Nov 2021

HAL is a multi-disciplinary open access archive for the deposit and dissemination of scientific research documents, whether they are published or not. The documents may come from teaching and research institutions in France or abroad, or from public or private research centers.
L'archive ouverte pluridisciplinaire HAL, est destinée au dépôt et à la diffusion de documents scientifiques de niveau recherche, publiés ou non, émanant des établissements d'enseignement et de recherche français ou étrangers, des laboratoires publics ou privés. 


\title{
Cyclic(Alkyl)(Amino)Carbene Ligands Enable Cu-Catalyzed Markovni- kov Protoboration and Protosilylation of Terminal Alkynes: A Versa- tile Portal to Functionalized Alkenes
}

Yang Gao, ${ }^{,, \neq}$Sima Yazdani, ${ }^{\S, *, \neq}$ Aaron Kendrick IV, ${ }^{\dagger}$ Glen P. Junor, ${ }^{\S}$ Douglas B. Grotjahn, ${ }^{*}$ Guy Bertrand,,${ }^{\S, *}$ Rodolphe Jazzar, ${ }^{\S, *}$ Keary M. Engle ${ }^{\dagger, *}$

${ }^{\dagger}$ Department of Chemistry, The Scripps Research Institute, 10550 North Torrey Pines Road, La Jolla, California 92037-1000, United States

${ }^{5}$ UCSD-CNRS Joint Research Laboratory (IRL 3555), Department of Chemistry and Biochemistry, University of California, San Diego, La Jolla, California 92093-0358, United States

* Department of Chemistry and Biochemistry, San Diego State University, 5500 Campanile Drive, San Diego, CA 92182-1030, United States.

\begin{abstract}
Regioselective hydrofunctionalization of alkynes represents a straightforward route to access alkenyl boronate and silane building blocks. In previously reported catalytic systems, high selectivity is achieved with a limited scope of substrates and/or reagents, with general solutions lacking. Herein, we describe a selective copper-catalyzed Markovnikov hydrofunctionalization of terminal alkynes that is facilitated by strongly donating cyclic (alkyl)(amino)carbene (CAAC) ligands. Using this method, both alkyl- and aryl-substituted alkynes are coupled with a variety of boryl and silyl reagents with high $\alpha$-selectivity. The reaction is scalable, and the products are versatile intermediates that can participate in various downstream transformations. Preliminary mechanistic experiments shed light on the role of CAAC ligands in this process.
\end{abstract}

\section{INTRODUCTION}

Alkenyl boronic acids and their derivatives are employed in a variety of stereospecific transformations, making them useful reagents in organic synthesis. ${ }^{1}$ Hydro- and protoboration of terminal alkynes are among the most straightforward approaches to prepare alkenyl boronic acid derivatives. ${ }^{2}$ Various transition metal catalysts have been developed to furnish linear $E$-alkenyl boron species with high $\beta$-selectivity, ${ }^{3}$ whereas methods to access branched $\alpha$-alkenyl boron species are more limited. ${ }^{4}$ Among existing procedures, few are highly Markovnikov-selective across different terminal alkynes and diverse boron sources. In a seminal study, Hoveyda demonstrated that the $\mathrm{Cu}$ complexes bearing NHC ligands (namely SIMes and SIPr) catalyze $\alpha$-selective protoboration of terminal alkynes using bis(pinacolato)diboron $\left(\mathrm{B}_{2} \mathrm{pin}_{2}\right)$ as a boron source (Scheme $\left.1 \mathrm{~A}\right) .{ }^{4 \mathrm{a}}$ However, the substrate scope was limited to alkyl-substituted alkynes bearing heteroatom substituents at the propargylic position (which have an inductively electron-withdrawing effect) and aryl-substituted alkynes bearing electron-withdrawing or -neutral substituents. Mechanistic studies indicate that the regiochemical outcomes in this system are governed in the migratory insertion step, where the copperboryl species adds across the $\mathrm{C} \equiv \mathrm{C}$ bond of the terminal alkyne (Scheme 1B). When alkynes bearing electron-donating substituents are used, the addition of the Lewis acidic boron moiety to the terminal carbon $\left(C_{\beta}\right)$ is more favored, due to the increased electron density at $\mathrm{C}_{\beta}$, leading to anti-Markovnikov selectivity. By attenuating the Lewis acidity of the boryl moiety, Yoshida developed an $\alpha$-selective protoboration of terminal alkynes where selectivity is independent of the electronic and steric properties of the alkyne (Scheme $1 \mathrm{~A}){ }^{4 c}$
Scheme 1. Overview of carbene-ligated Cu-catalyzed $\alpha$-selective protoboration of terminal alkynes.

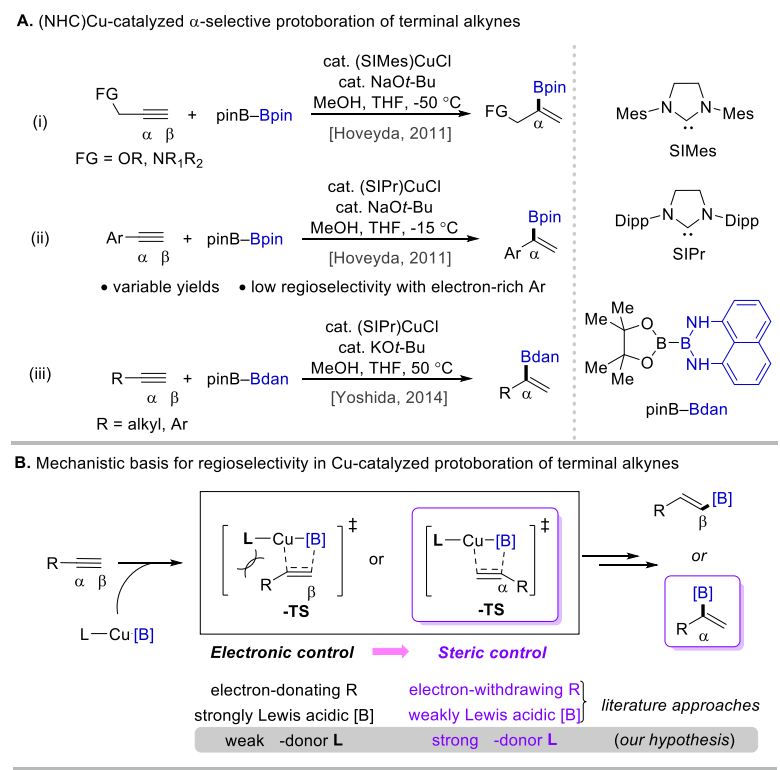

C. (CAAC)Cu-catalyzed $\alpha$-selective protoborylation/silylation of terminal alkynes (this work)

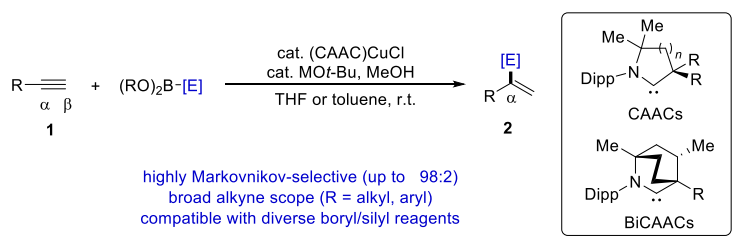


However, this method requires the use of the expensive masked diboron reagent pinB-Bdan (dan = naphthalene-1,8-diaminato), and the alkenyl-Bdan products normally require an extra unmasking step before further transformation. Inspired by Yoshida's boroncontrolled strategy, we reasoned that a more strongly electron-donating ancillary ligand could potentially offset the Lewis acidity of more commonly encountered boryl groups (e.g., Bpin) and provide a means of controlling regioselectivity in a manner that is independent of the electronic nature of both the alkyne substrate and the diboron reagent (Scheme 1B). Over the past several years, ${ }^{5}$ the Bertrand lab has developed a number of cyclic (alkyl)(amino)carbene (CAACs) ligands, ${ }^{6,7,89}$ which show unique reactivity and selectivity profiles in several transition-metal-catalyzed reactions. ${ }^{10}$ Given that these ligands are known to be stronger $\sigma$-donors than analogous NHCs ligands, ${ }^{11}, 12$ we hypothesized that the corresponding $\mathrm{LCu}\left(\mathrm{BX}_{2}\right)$ species would undergo preferential Markovnikov-selective addition to terminal alkynes via $\boldsymbol{\alpha}$-TS. Herein we describe a highly $\alpha$-selective protoboration of terminal alkynes catalyzed by CAAC-ligated $\mathrm{Cu}$ complexes (Scheme 1C). In addition to tolerating a wide range of alkyl- and aryl-substituted alkynes, the protocol can also be applied to install a variety of boron moieties. The generality of this CAAC-controlled Markovnikov-selectivity is demonstrated through the realization of an analogous protosilylation method with pinB-SiMe ${ }_{2} \mathrm{Ph},{ }^{13}$ whereas NHC ligands, such as SIMes and SIPr, gave exclusive $\beta$-selectivity. ${ }^{14}$

\section{RESULTS AND DISCUSSION}

1. Reaction Optimization. To initiate our study, we first selected 5phenyl-1-pentyne (1a) as the model substrate, $\mathrm{B}_{2} \mathrm{pin}_{2}$ as the boron coupling partner, $\mathrm{MeOH}$ as the proton source, $\mathrm{NaO} t$ - $\mathrm{Bu}$ as the base, and THF as the solvent and carried out the reaction at room temperature. As summarized in Table 1, a select number of CAAC-ligated $\mathrm{Cu}$ complexes were examined for their ability to promote formation of 2a. To our delight, ${ }^{E t} \mathrm{CAAC}_{5}$-ligated $\mathrm{Cu}$ complex $\left(\mathrm{L}_{1} \mathrm{CuCl}\right)$ promotes the transformation with $92 \%$ a-selectivity. Replacement of the ethyl groups on the $\alpha$-carbon of $L_{1}$ with either an electron-withdrawing group $\left(\mathbf{L}_{2}\right)$ or a more sterically bulky group $\left(\mathbf{L}_{3}\right)$ did not lead to further improvement. ${ }^{E t} \mathrm{CAAC}_{6}$ ligand $\left(\mathrm{L}_{4}\right)$, a much stronger electron-donor than $L_{1}$, gave the highest $\alpha: \beta$ ratio (94:6). Along these lines, BiCAAC ligands, ${ }^{i{ }_{1}} \mathrm{BiCAAC}\left(\mathbf{L}_{\mathbf{s}}\right)$ and ${ }^{\text {PhE }} \mathrm{BiCAAC}\left(\mathbf{L}_{\mathbf{6}}\right)$, which are also strong electron-donors,

\section{Table 1. Optimization of reaction conditions $\mathrm{s}^{\mathrm{a}}$}

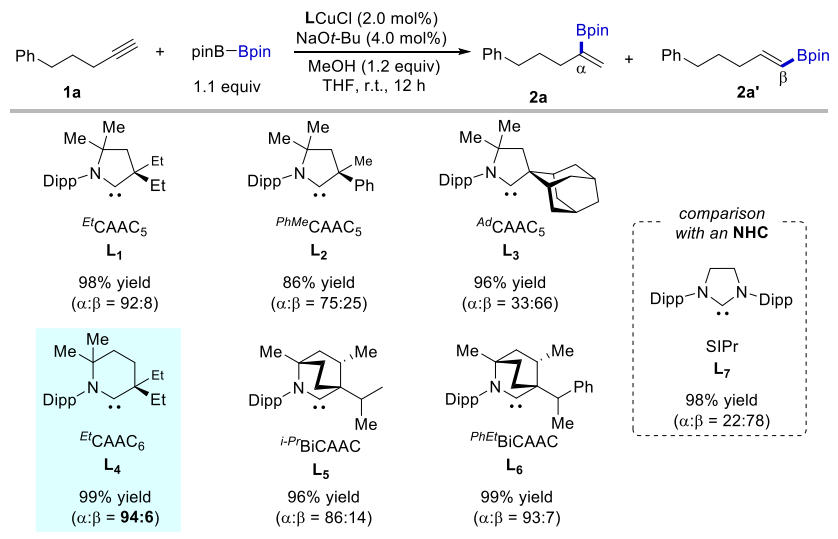

aYields of products $(\alpha+\beta)$ and regioselectivity $( \pm 2 \%)$ were determined by ${ }^{1} \mathrm{H}$ NMR $(600 \mathrm{MHz})$ using $\mathrm{CH}_{2} \mathrm{Br}_{2}$ as the internal standard. furnished the desired product $2 \mathrm{a}$ with high, although slightly attenuated $\alpha$-selectivity of $86 \%$ and $93 \%$, respectively. For comparison, an $\mathrm{NHC}$ variant, namely SIPr-ligated $\mathrm{Cu}$ complex $\mathrm{L}_{7} \mathrm{CuCl}$, only delivered $22 \%$ of the $\alpha$-isomer $\mathbf{2 a}$ under the identical reaction conditions.

2. Substrate Scope. We then evaluated the scope with respect to alkyl-substituted alkynes using $\mathrm{L}_{4} \mathrm{CuCl}$ as the precatalyst (Table 2). Alkynes containing different primary alkyl chains readily underwent efficient Markovnikov-selective protoboration (2a and 2c). A wide range of functional groups, including halide $(\mathbf{2 b})$, cyano $(\mathbf{2 d})$, carboxyl (2e) and hydroxyl (2j) groups, were tolerated, with products isolated in excellent yields and high regioselectivity. Substrates containing different methylene spacer lengths $(n=1-4)$ between the

Table 2. Scope of $\alpha$-selective protoboration of terminal alkyl-substituted alkynes

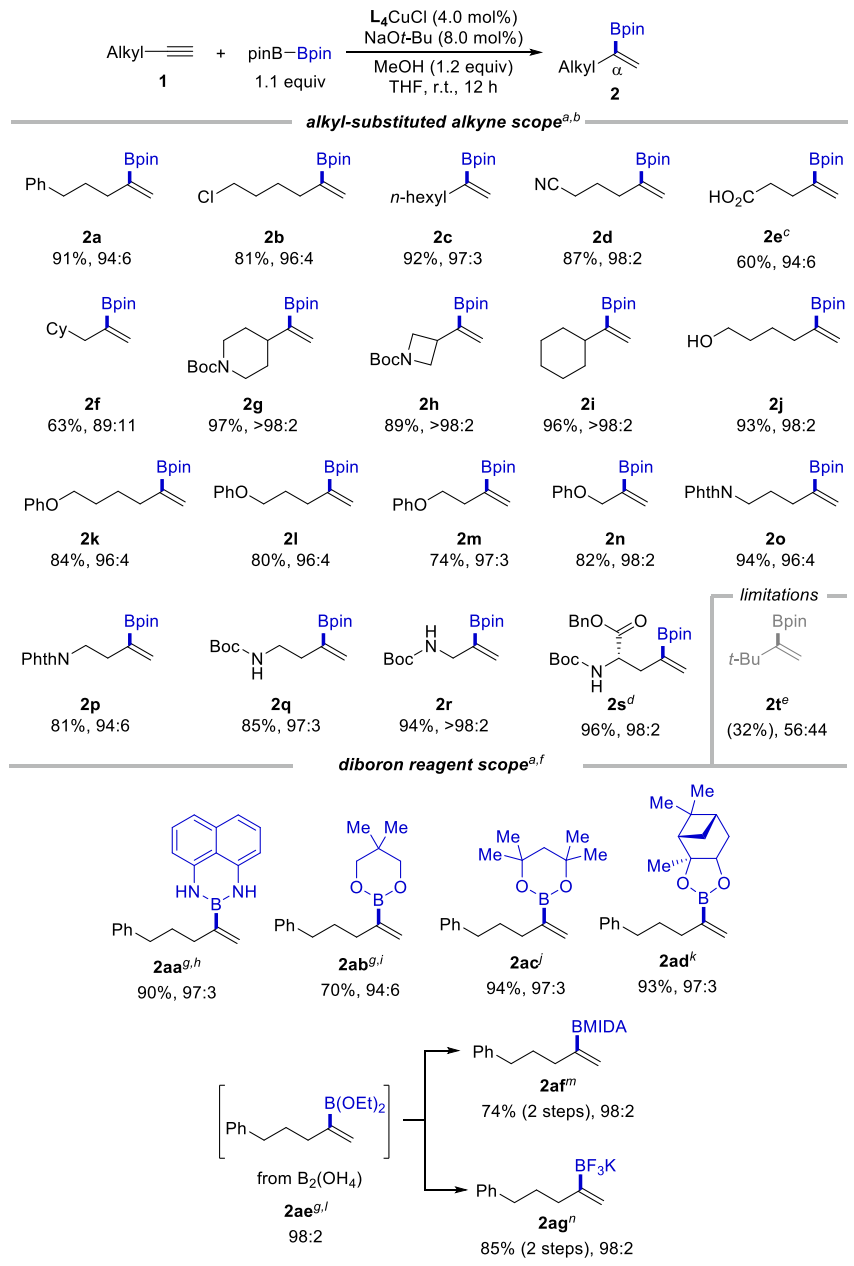

${ }^{a}$ Ratios of $\alpha: \beta( \pm 2 \%)$ were determined via ${ }^{1} \mathrm{H}$ NMR $(600 \mathrm{MHz})$ of the crude reaction mixture. Percentages represent isolated yields of the $\alpha$-borylated products. ${ }^{b} \mathrm{Condi}$ tions: $1(0.10 \mathrm{mmol}), \mathrm{B}_{2} \mathrm{pin}_{2}(0.11 \mathrm{mmol}), \mathrm{L}_{4} \mathrm{CuCl}(0.004 \mathrm{mmol}), \mathrm{NaO} t$ - $\mathrm{Bu}(0.008$ $\mathrm{mmol}), \mathrm{MeOH}(0.12 \mathrm{mmol})$ and THF $(0.50 \mathrm{~mL})$, r.t. ${ }^{\mathrm{NaO}} t$-Bu (1.1 equiv); the product was esterfied before isolation. ${ }^{d} 98 \%$ ee obtained from 1 s of $99 \%$ ee. ${ }^{e}$ Percentage represents ${ }^{1} \mathrm{H} \mathrm{NMR}(600 \mathrm{MHz})$ yields of the $\alpha$-borylated isomer using $\mathrm{CH}_{2} \mathrm{Br}_{2}$ as the internal standard. ${ }^{f}$ Conditions: $1 \mathrm{a}(0.10 \mathrm{mmol})$, diboron reagent $(0.11 \mathrm{mmol}), \mathrm{L}_{4} \mathrm{CuCl}$ $(0.004 \mathrm{mmol}), \mathrm{NaO} t$-Bu $(0.008 \mathrm{mmol}), \mathrm{MeOH}(0.12 \mathrm{mmol})$ and THF $(0.50 \mathrm{~mL})$, r.t.. ${ }^{g} \mathrm{~L}_{1} \mathrm{CuCl}(2.0 \mathrm{~mol} \%)$ and $\mathrm{NaO} t-\mathrm{Bu}(4.0 \mathrm{~mol} \%)$. ${ }^{h}$ pinB-Bdan (1.1 equiv). ${ }^{i} \mathrm{~B}_{2} \mathrm{nep}_{2}$ (1.1 equiv). ${ }^{\prime} \mathrm{B}_{2}(\mathrm{dmpd})_{2}$ (1.1 equiv). ${ }^{\mathrm{k}} \mathrm{Bis}[(-)$ pinanediolato $]$ diboron (1.1 equiv). $\mathrm{L}_{1} \mathrm{CuCl}$ (2.0 mol\%), $\mathrm{NaO} t$ - $\mathrm{Bu}\left(0.3\right.$ equiv), $\mathrm{B}_{2}(\mathrm{OH})_{4}(1.2$ equiv), EtOH $(0.25 \mathrm{~mL})$ and THF $(0.25 \mathrm{~mL})$, r.t., $6 \mathrm{~h} .{ }^{m}$ Conditions: methyliminodiacetic acid $(3.0$ equiv), toluene/DMSO, $105{ }^{\circ} \mathrm{C}$. ${ }^{n}$ Conditions: $\mathrm{KHF}_{2}$ aqueous solution (6.0 equiv), $\mathrm{MeOH}, 0{ }^{\circ} \mathrm{C}$ to r.t.. 
$\mathrm{C} \equiv \mathrm{C}$ bond and a heteroatom group, such as ethers $(\mathbf{2 k}-\mathbf{2 n})$ or protected amino groups (20-2r), all underwent protoboration in 94 $98 \% \alpha$-selectivity and $74-94 \%$ yield. The reactions of alkynes bearing secondary alkyl groups at the $\alpha$-position $(\mathbf{2 g}-\mathbf{2 i})$ gave especially high Markovnikov selectivity. However, increasing steric hindrance further with a tertiary alkyl group is deleterious, as seen with the reactivity of the $t$-butyl acetylene under the optimal conditions (2t). Alkynes with functional groups like pendant piperidine, azetidine, and glycine, commonly found in medicinally relevant molecules were all competent reactants $(\mathbf{2} \mathbf{g}, \mathbf{2} \mathbf{h}$ and $\mathbf{2 s})$.

The generality of this reaction was further evaluated by exploring a range of diboron reagents. pinB-Bdan was subjected to the reaction conditions, affording product 2 aa in $64 \%$ yield and $97 \% \alpha$-selectivity. When $\mathrm{L}_{1} \mathrm{CuCl}$ was used, the yield of 2 aa was improved to $90 \%$ with the same $\alpha: \beta$ ratio observed. A range of diboron esters performed well, allowing the highly regioselective synthesis of $\alpha$-alkenyl boronates (2ab-2ad). The reaction using $\mathrm{B}_{2}$ nep $_{2}$ also required $\mathrm{L}_{1} \mathrm{CuCl}$ as the catalyst to obtain a good yield. It is worth noting that $\mathrm{B}_{2}(\mathrm{OH})_{4}$ was a competent partner, furnishing 2 ae with $98: 2 \alpha$ : $\beta$ ratio under slightly modified reaction conditions, in which $\mathrm{EtOH}$ was

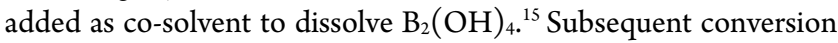
of the $\mathrm{B}(\mathrm{OEt})_{2}$ group into $\mathrm{BMIDA}$ and $\mathrm{BF}_{3} \mathrm{~K}$ groups furnished $2 \mathrm{af}$ ( $74 \%$ yield) and $\mathbf{2 a g}$ ( $85 \%$ yield), respectively, over two steps.

We next sought to develop a method for Markovnikov-selective protoboration of terminal aryl-substituted alkynes. After a brief screening of CAAC and BiCAAC ligands, ${ }^{\text {PhE }}$ BiCAAC $\left(\mathbf{L}_{6}\right)$ was found to give the highest $\alpha$ : $\beta$ ratio (94:6) with phenylacetylene (1u) as substrate (see SI for additional data). The effect of aromatic substituents on $\mathrm{L}_{6} \mathrm{Cu}$-catalyzed protoboration was examined and further compared with that of (SIPr)Cu-catalyzed reactions (Table 3 ). To our delight, $\mathrm{L}_{6} \mathrm{CuCl}$ consistently gave the branched compounds

Table 3. Scope of $\alpha$-selective protoboration of terminal aryl-substituted alkynes. ${ }^{a}$

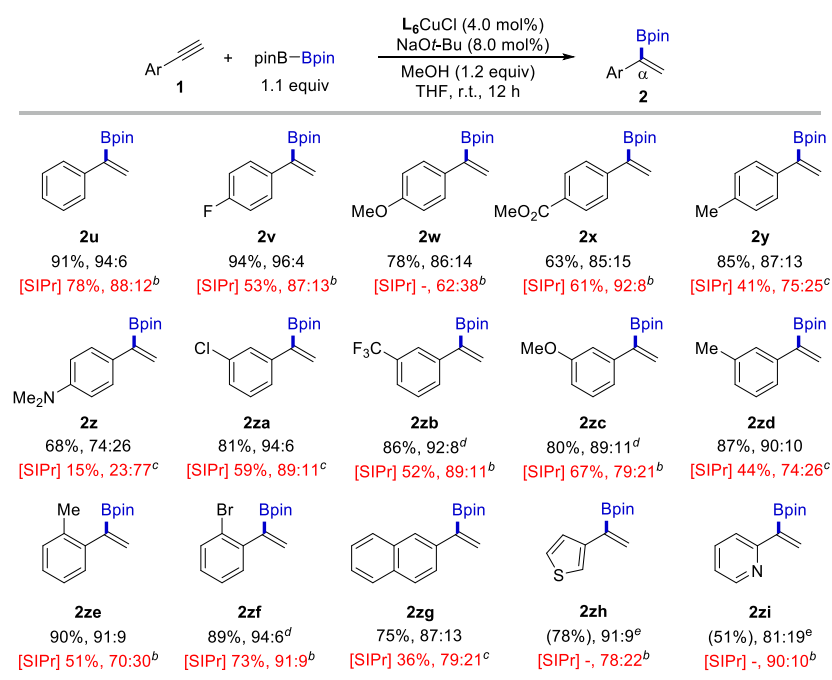

${ }^{a}$ Conditions: 1 (0.10 mmol), $\mathrm{B}_{2} \operatorname{pin}_{2}(0.11 \mathrm{mmol}), \mathrm{L}_{6} \mathrm{CuCl}(0.005 \mathrm{mmol}), \mathrm{NaO} t$ - $\mathrm{Bu}$ $(0.010 \mathrm{mmol}), \mathrm{MeOH}(0.12 \mathrm{mmol})$ and THF $(0.50 \mathrm{~mL})$, r.t. Ratios of $\alpha: \beta( \pm 2 \%)$ were determined via ${ }^{1} \mathrm{H}$ NMR $(600 \mathrm{MHz})$ of the crude reaction mixtures. Percentages represent isolated yields of the $\alpha$-borylated products. ${ }^{b}$ Reported results from Ref $4 a$. ${ }^{C}$ Results using reaction conditions from Ref. $4 \mathrm{a}$; percentages represent ${ }^{1} \mathrm{H}$ NMR yields of the $\alpha$-borylated products. ${ }^{d} \mathrm{KO} t$-Bu $(10 \mathrm{~mol} \%)$ and toluene $(0.50 \mathrm{~mL}) .{ }^{e}$ Percentages represent ${ }^{1} \mathrm{H} \mathrm{NMR}\left(600 \mathrm{MHz}\right.$ ) yields of the $\alpha$-borylated products using $\mathrm{CH}_{2} \mathrm{Br}_{2}$ as the internal standard. The isolated yield was not obtained due to complication during the isolation. as the major products with high yields, whereas variable regioselectivity and yields were observed in ( $\mathrm{SIPr}) \mathrm{Cu}$-catalyzed reactions. This difference in performance is most evident in the case of $p$ $\mathrm{NMe}_{2}$-phenylacetylene as substrate, where $74: 26 \alpha: \beta$ ratio and $68 \%$ yield were observed in the $\mathrm{L}_{6} \mathrm{Cu}$-catalyzed reaction, while the $\mathrm{NHC}$ ligaged $\mathrm{L}_{7} \mathrm{CuCl}$ catalyst led to only 23:77 $\alpha$ : $\beta$ ratio and $15 \%$ yield $(2 z)$. Reactions with aryl alkynes that bear an $o-\mathrm{Me}$ or $o-\mathrm{Br}$ performed well with 91-94\% a-selectivity observed (2ze-2zf). 2Ethynyl-naphthalene and 3-ethynyl-thiophene underwent efficient $\boldsymbol{\alpha}$-selective protoboration $(\mathbf{2 z g}-\mathbf{2 z h})$, while reaction of 2-ethnylpyridine gave a slightly lower $\alpha$-selectivity of $81 \%$ (2zi).

3. Product Transformations. Upon scaling up the reaction using 1a $(4.0 \mathrm{mmol})$ as the substrate, two representative protoboration reactions proceeded smoothly, furnishing 2 a in $81 \%$ yield and 2 af in $60 \%$ yield over two steps. The Bpin group of $\mathbf{2 a}$ is readily converted to a variety of functional groups, enabling access to other valuable $\alpha$-substituted alkenes, including $\alpha$-halogenated alkenes (3aa-3ab) and $\alpha$ arylated alkenes (3ac). Moreover, the resulting alkene is amenable to a variety of diversifications. We were able to synthesize a 1,3-bis(boryl)alkane 3ad via a boronic ester induced bis-1,2-migration pathway, following Studer's procedure. ${ }^{16}$ In addition, Fe-catalyzed HAT olefin cross-coupling reaction between $2 \mathrm{a}$ and $N, N$-dimethylacrylamide gave 3ae in useful yield, under Baran's conditions with slight modifications. ${ }^{17}$ Finally, with $\mathrm{mCPBA}$ as an oxidant, epoxidation of 2 af giving 3 af was achieved in $89 \%$ yield. ${ }^{18}$

\section{Scheme 2. Scale up and diversification.}

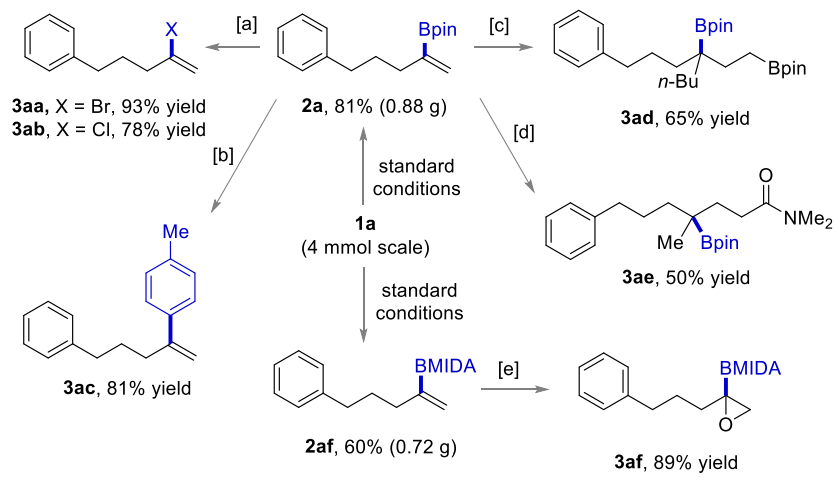

Conditions: [a] $\mathrm{CuX}, \mathrm{MeOH} / \mathrm{H}_{2} \mathrm{O}, 90^{\circ} \mathrm{C}$. [b] $10 \% \mathrm{Pd}\left(\mathrm{PPh}_{3}\right)_{4}, \mathrm{Cs}_{2} \mathrm{CO}_{3}$, p-iodotoluene, THF, $65^{\circ} \mathrm{C}$. [c] $n$ - BuLi, $\mathrm{Et}_{2} \mathrm{O}, 0{ }^{\circ} \mathrm{C}$ to r.t., then $\mathrm{ICH}_{2} \mathrm{Bpin}, \mathrm{MeCN}$, r.t. [d] $5 \%$ $\mathrm{Fe}(\text { acac })_{3}, \mathrm{Na}_{2} \mathrm{HPO}_{4}, \mathrm{Ph}(i$-PrO $) \mathrm{SiH}_{2}, N, N$-dimethylacrylamide, EtOH, $65{ }^{\circ} \mathrm{C}$. [e] $m \mathrm{CPBA}, \mathrm{DCM}, 0^{\circ} \mathrm{C}$ to r.t. under air.

4. Protosilylation. To further explore the CAAC/BiCAACcontrolled regioselectivity in $\mathrm{Cu}$-catalyzed hydrofunctionalization chemistry, we turned our attention to protosilylation of terminal alkynes. ${ }^{19}$ Though the NHC-ligated copper complex, (SIMes) $\mathrm{CuCl}$, has been demonstrated to catalyze such a reaction, exclusive antiMarkovnikov-selectivity was observed across a broad collection of terminal alkynes (Scheme 3) ${ }^{14}$ On the other hand, Markovnikov-selective $\mathrm{Cu}$-catalyzed protosilylation of aliphatic alkynes was reported by Loh, using JohnPhos as the ligand..$^{20}$ Although highly enabling in its own right, Loh's method has notable drawbacks, including modest performance with alkynes bearing heteroatom groups at the propargylic or homopropargylic position and significantly decreased regioselectivity with phenylacetylene as substrate. 
Scheme 3. Selected examples of $\mathrm{Cu}$-catalyzed protosilylation of terminal alkynes

A. (SIMes)Cu-catalyzed $\beta$-selective protosilylation

$$
\begin{aligned}
& \text { cat. (SIMes) CuCl } \\
& \text { cat. } \mathrm{NaOt} \text {-Bu, } \\
& \mathrm{R} \underset{\alpha \beta}{\overline{\overline{\alpha \beta}}}+\operatorname{pinB}-\mathrm{SiMe}_{2} \mathrm{Ph} \underset{[\text { Hoveyda, 2013] }}{\stackrel{\mathrm{MeOH}, \mathrm{THF}, 2{ }^{\circ} \mathrm{C}}{\longrightarrow}} \underset{\mathrm{R}}{\mathrm{SiMe}_{2} \mathrm{Ph}} \\
& \mathrm{R}=\mathrm{alkyl}, \mathrm{Ar}
\end{aligned}
$$

B. (Johnphos)Cu-catalyzed $\alpha$-selective protosilylation

$$
\mathrm{R} \frac{\overline{\bar{\equiv} \beta}}{\bar{\equiv}}+\operatorname{pinB}-\mathrm{SiMe}_{2} \mathrm{Ph} \stackrel{\begin{array}{c}
\text { cat. } \mathrm{CuCl} \text {, cat. } \mathrm{NaOt}-\mathrm{Bu} \\
\text { cat. JohnPhos ligand } \\
\mathrm{MeOH}, \mathrm{THF}, 0{ }^{\circ} \mathrm{C}
\end{array}}{[\text { Loh, 2011] }}
$$

- low reactivity with heteroatom groups at propargyl or homopropargyl position - low regioselectivity with $\mathrm{Ph}$-acetylene

In our initial experiments we attempted to adapt the reaction conditions for protoboration to protosilylation by enlisting pinB$\mathrm{SiMe}_{2} \mathrm{Ph}$ as the nucleophilic silyl source. Different CAACs and BiCAACs ligands were examined, and $\mathbf{L}_{4}$ was found to give the highest $\alpha: \beta$ ratio (97:3), providing product $4 \mathrm{a}$ in $55 \%$ yield (see SI for additional data). After brief optimization, we identified conditions for $\alpha$ selective protosilylation of terminal alkynes (Table 4). Heteroatom groups like ether or a protected amine group on the propargylic or homopropargylic position had little effect on reactivity, with products (4b-4c) obtained in excellent yields (86-93\%) and high $\alpha$-selectivity (91-95\%). We then tested the scope of aryl-substituted alkynes. The $\mathrm{L}_{4} \mathrm{CuCl}$-catalyzed protosilylation of phenylacetylene delivered the branched product $4 \mathrm{~d}$ with $91 \%$-selectivity. Reactions of $p$-, $m$ - and $o$-tolylacetylene proceed with excellent yield (75-93\%) and high $\alpha$-selectivity (89-95\%) (4f, $4 \mathbf{i}$ and $\mathbf{4 k}$ ). In contrast to what we observed in our study of protoboration, electron-deficient aryl groups have a negative impact on the selectivity for formation of the

Table 4. Scope of $\alpha$-selective protosilylation of terminal alkynes ${ }^{a}$

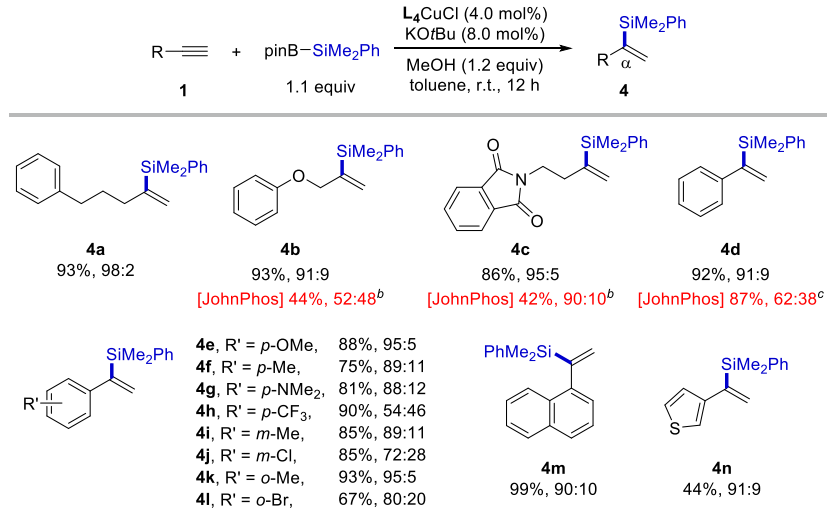

${ }^{a}$ Conditions: 1 (0.10 mmol), pinB-SiMe $2 \mathrm{Ph}(0.11 \mathrm{mmol}), \mathrm{L}_{4} \mathrm{CuCl}(0.004 \mathrm{mmol})$, $\mathrm{KO} t$ - $\mathrm{Bu}(0.008 \mathrm{mmol}), \mathrm{MeOH}(0.12 \mathrm{mmol})$ and toluene $(0.50 \mathrm{~mL})$, r.t. Ratios of $\alpha: \beta$ $( \pm 2 \%)$ were determined via ${ }^{1} \mathrm{H}$ NMR $(600 \mathrm{MHz})$ of the crude reaction mixtures. Percentages represent combined yields of the two regioisomers, which were inseparable and isolated together. ${ }^{b}$ Results using method in Ref. 19 . ${ }^{\circ}$ Reported results from Ref. 19.

$\alpha$-silylated products. For instance, reactions of aryl alkynes bearing $p-\mathrm{CF}_{3}$ or $m-\mathrm{Cl}$ groups gave 54:46 and 72:28 $\alpha: \beta$ ratios, respectively. Electron-donating aryl substituents, such as $p$-OMe and $p-\mathrm{NMe}_{2}$, on the other hand, gave rise to higher $\alpha$-selectivity $(4 \mathrm{e}$ and $\mathbf{4 g}) .{ }^{21} 2$ Ethynyl-naphthalene and 3-ethynyl-thiophene were also competent partners ( $4 m$ and $4 n$ ), though the latter gave only moderate yield.

5. Mechanistic Studies. As previously reported, site selectivity in ( $\mathrm{NHC}$ ) Cu-catalyzed protoboration of terminal alkynes is governed by the structure of the NHC ligand and the substrate. ${ }^{4}$ To better understand the conspicuous catalytic differences observed with CAAC ligands, a preliminary mechanistic study was performed.

Ligand effect. Contrasting with our initial hypothesis and as highlighted in Scheme 4A using $L_{1}, L_{3}, L_{4}$ and $L_{5}$, a trend rationalizing the $\alpha$-selectivity obtained across CAAC motifs from their respective $\sigma$ donating properties alone is not straightforward. ${ }^{22}$ Intrigued by the reversed selectivity observed with the rigid and bulky adamantyl

\section{Scheme 4. Highlighting the influence of steric and electronic parameters in the (CAAC)copper-catalyzed protoboration of alkynes}

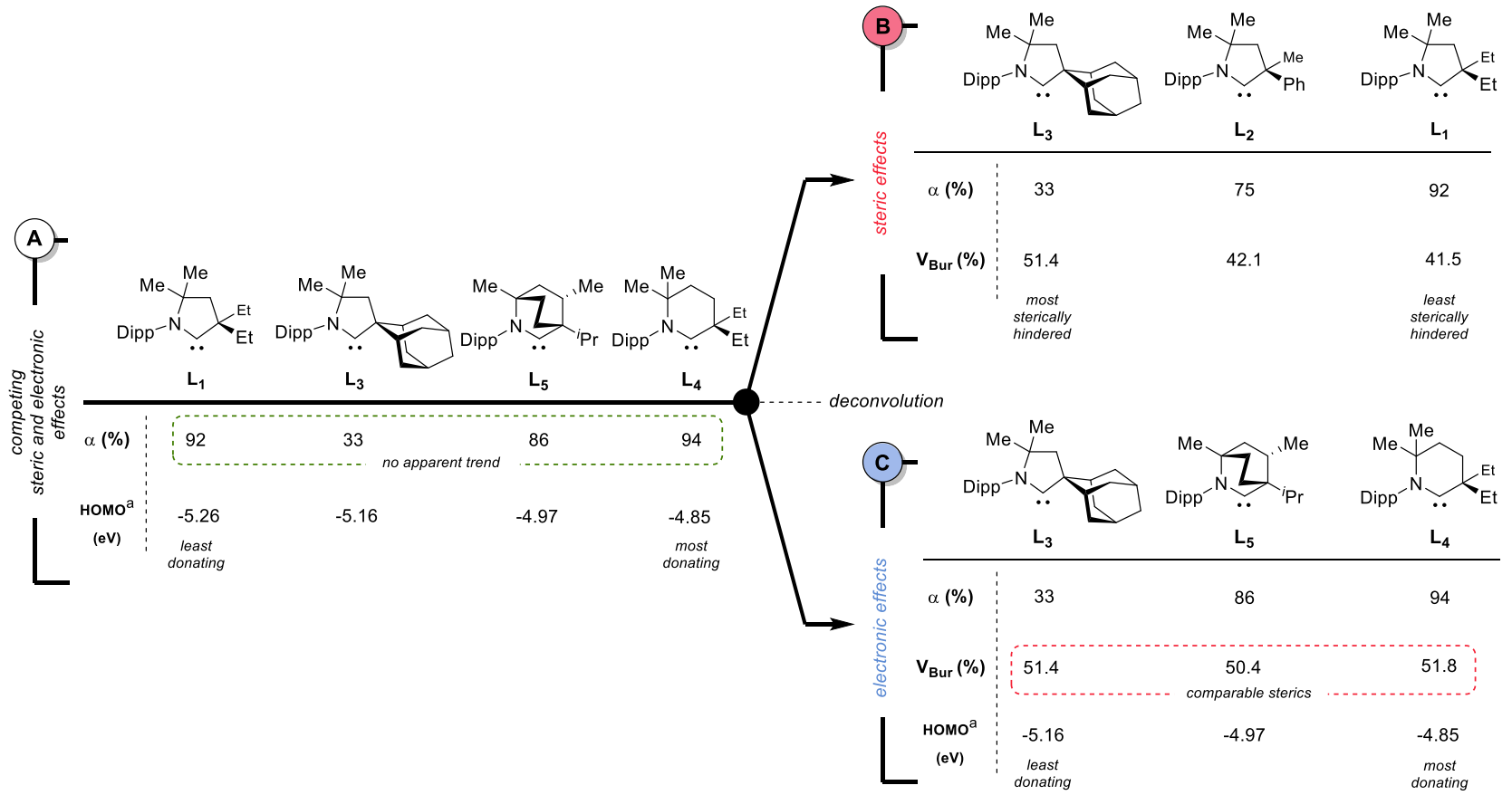


CAAC $_{5} \mathbf{L}_{3}$ (Table 1), we wondered if the steric and the electronic environment of the CAAC ligands could have conflicting influences. To deconvolute these effects, we first considered the CAAC $\mathrm{C}_{5}$ ligands $\mathbf{L}_{1}-\mathrm{L}_{3}$, bearing comparable electronic environments and noted the $\alpha$-selectivity to increase with decreasing steric hindrance (Scheme 4B). ${ }^{23,24}$ We next examined CAAC ligands $\mathbf{L}_{3}-\mathbf{L}_{5}$ with comparable steric environments, and in this case confirmed that increasing $\sigma$-donation of the CAAC ligands favor $\alpha$-selectivity (Scheme 4C). Taken together these observations clarify the higher $\alpha$-selectivity obtained with the more donating BiCAAC and $\mathrm{CAAC}_{6}$ ligands, which also benefit from a flexible steric environment that is more amenable to substrate modularity. ${ }^{6,25,26}$ Note that these observations contrast with previous reports using NHC ligands in which the $\alpha$ vs. $\beta$-selectivity was rationalized through the respective electronic properties of the ligands (i.e. $\beta$-selectivity for SIAd : HOMO $=-5.34 \mathrm{eV}$; $\alpha$-selectivity for SIMes : HOMO $=-5.70 \mathrm{eV}) .{ }^{27}$ While more studies will be needed to clarify these competing effects, it is possible that steric hindrance is also at play in this scenario. ${ }^{28}$

Alkyne effect. As noted previously, our results suggest that CAAC ligands are more impervious to the nature of the reagents compared to NHCs. To confirm this trend, a Hammett correlation study was performed to quantify the electronic influence of the substrates in the protoborylation of arylacetylenes catalyzed by copper complexes of $\mathbf{L}_{6}\left({ }^{P h E}{ }^{\mathrm{BiCAAC}}\right)$ and $\mathbf{L}_{7}$ (SIPr) (Scheme 5) ${ }^{29}$ In either catalytic system, high $\alpha$-selectivity was observed in the presence of electronneutral or -deficient aryl groups $(\sigma \geq 0)$, while it dropped when electron-rich aryl groups were used. As a result, positive values for $\Delta \rho\left(\rho_{\alpha}\right.$ $-\rho_{\beta}$ ) were obtained with both SIPr and ${ }^{\text {PhE }}$ BiCAAC ligands. Though there does seem to be some influence as one moves from electronneutral to highly electron-donating, the significantly smaller $\Delta \rho$ obtained with $\operatorname{BiCAAC}\left(\Delta \rho_{\mathrm{BiCAAC}}=0.43\right.$ vs. $\left.\Delta \rho_{\mathrm{SIPr}}=1.2\right)$, together with a weaker $\log (\alpha / \beta)$ vs. $\sigma$ correlation $\left(\mathrm{R}_{\text {BiCAAC }}^{2}=0.38\right.$ vs. $\left.\mathrm{R}_{\text {SIPr }}^{2}=0.90\right)$ supports the notion that with CAAC ligands there is no longer as strong of a relationship between the variables of electronic character and regioselectivity.
Mechanism. While the mechanism of the protoboration involving copper-boryl intermediates has been thoroughly studied with NHC ligands, ${ }^{4}$ much less is known about the corresponding protosilylation reaction, and nothing is known yet about either of these reactions with CAAC-based catalysts. It is generally accepted, however, that both pathways proceed through the same catalytic sequence as highlighted in Scheme 6A starting from $\mathrm{L}_{4} \mathrm{CuCl}^{30}$ To further our understanding of (CAAC) Cu-catalyzed hydrofunctionalization of alkynes, stoichiometric reactions were performed. As shown in Scheme $6 \mathrm{~B}$ reaction of $\mathrm{L}_{4} \mathrm{CuCl}$ with one equivalent of $\mathrm{KOPh}$ afforded the corresponding copper-phenoxide $\mathbf{A}^{\prime}$, which underwent anion metathesis with $\mathrm{B}_{2} \mathrm{Pin}_{2}$ to generate the corresponding

Scheme 5. Comparatively to SIPr, the ${ }^{P h M e} \mathrm{BiCAAC}$ copper catalyst is more impervious to alkynes' electronic properties.

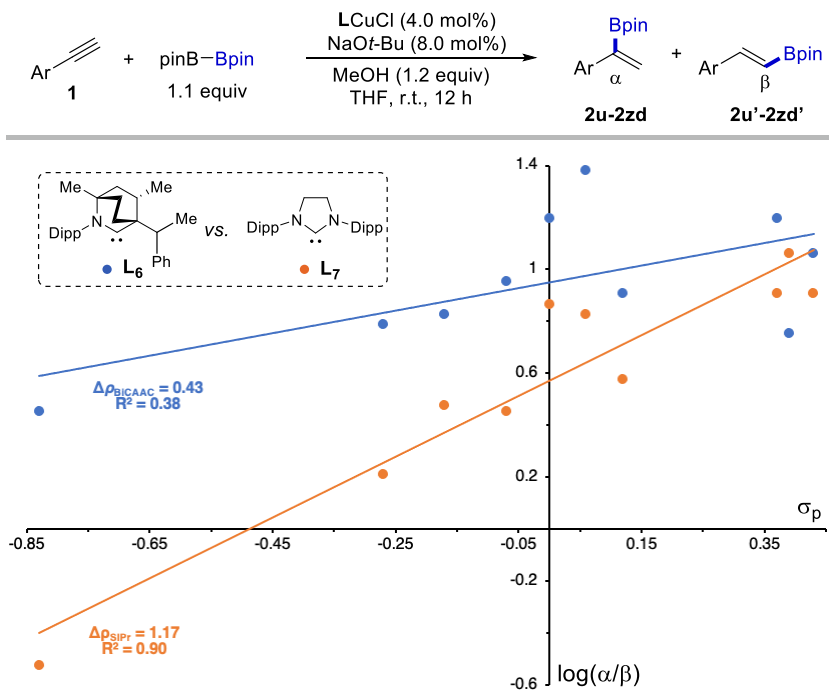

Scheme 6. Proposed mechanism (A) and mechanistic studies (B and C).
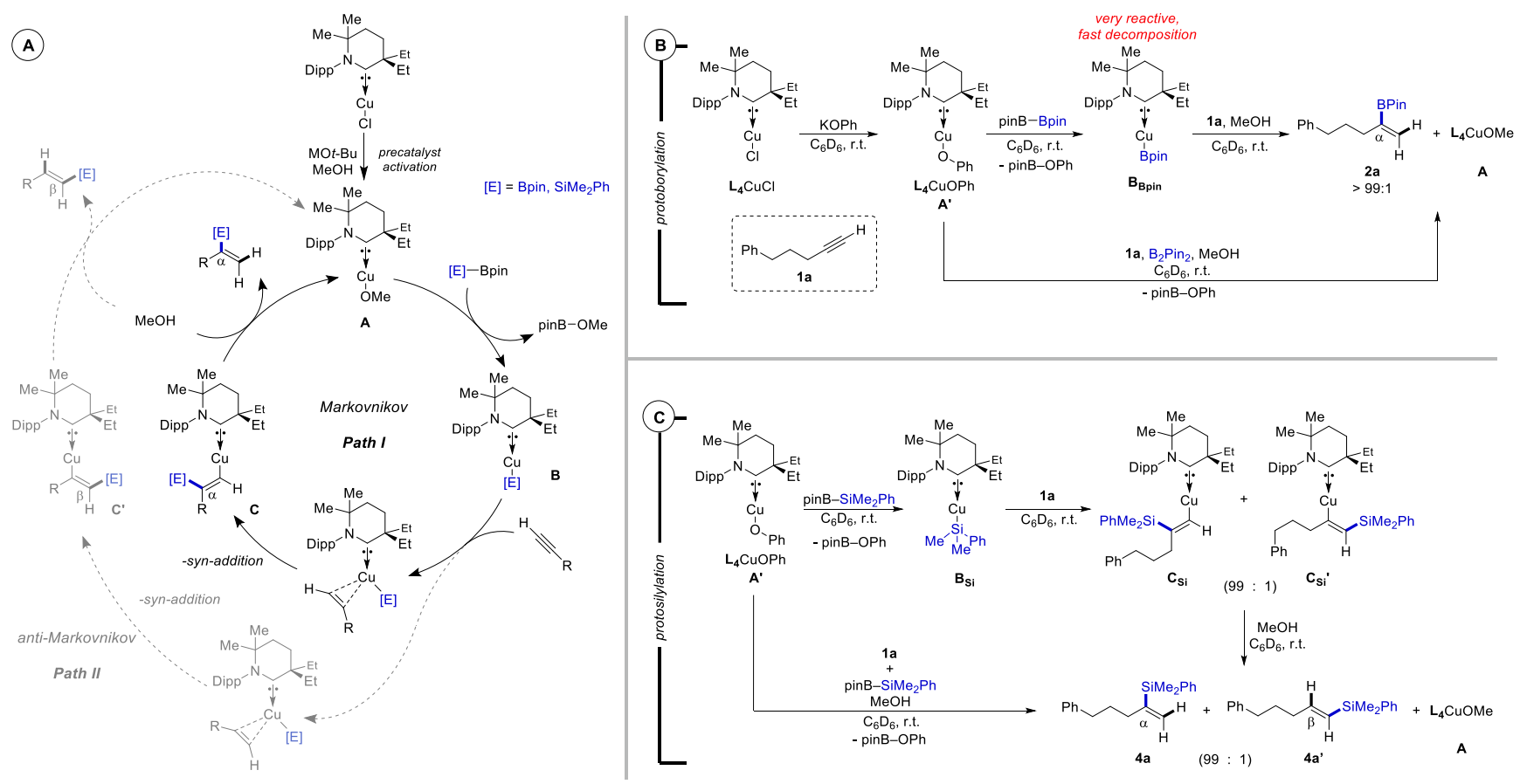
copper-boryl $\mathbf{B}_{\text {Bpin }}$ with a characteristic ${ }^{11} \mathrm{~B}$ NMR signal at 43.5 ppm. ${ }^{31}$ In our hands the copper-boryl $\mathbf{B}_{\mathrm{Bpin}}$ proved too reactive to be handled; however, upon addition of alkyne $1 \mathbf{a}$ and $\mathrm{MeOH}$ ( 2 equiv), the desired $\alpha$-borylated product $\mathbf{2 a}$ was obtained with $99 \%$ selectivity. To confirm these results under pseudo-catalytic conditions, complex $\mathbf{A}^{\prime}$ was reacted with a mixture of $\mathrm{B}_{2} \mathrm{Pin}_{2}, \mathbf{1} \mathbf{a}$ and $\mathrm{MeOH}$, affording the same selectivity.

Turning our attention to the protosilylation reaction, we found that reaction of $\mathbf{A}$ with pinB-SiMe ${ }_{2} \mathrm{Ph}$ afforded the comparatively more stable copper-silyl intermediate $\mathbf{B}_{\mathrm{Si}}$, which could be characterized by NMR spectroscopy Scheme $6 \mathrm{~B} .{ }^{32}$ More interestingly, addition of alkyne 1a to this complex led to the formation of 99:1 mixture of $\alpha$ - and $\beta$-silylorganocopper intermediates $\mathbf{C}_{S_{\mathrm{i}}}$ and $\mathbf{C}_{\mathbf{S i}^{\prime}}$, respectively. Subsequent protonolysis with $\mathrm{MeOH}$ afforded the corresponding protosilylated products $\mathbf{4 a}$ and $\mathbf{4 a}$ ' in the same ratio. Note that protonolysis with $\mathrm{MeOD}$ led to selective deuteration in the same positions, supporting a similar mechanism as seen for the protoboration reaction. Here also we could recapitulate these results under pseudo-catalytic conditions by reacting complex $\mathbf{A}$ with a mixture of pinB-SiMe ${ }_{2} \mathrm{Ph}, 1 \mathrm{a}$ and $\mathrm{MeOH}$. Beyond supporting the postulated catalytic cycle, these preliminary mechanistic studies suggest that in this system the steric and electronic environment of the CAACs governs the regiochemical outcome by controlling the coordination of the alkyne substrate and the ensuing migratory insertion step.

\section{CONCLUSION}

In conclusion, we have developed a selective method for accessing Markovnikov alkenyl boronic and silanes building blocks. It tolerates both electron-rich and electronic-deficient alkynes as well as a range of boryl and silyl reagents. Gram-scale synthesis allowed for the diversification of these building blocks into value-added chemicals. Furthermore, preliminary mechanistic studies suggest that the steric and electronic environment of the ligand have competing effects, with the Markovnikov hydrofunctionalization preferring the sterically flexible and most donating $\mathrm{BiCAAC}_{\mathrm{C}}$ and $\mathrm{CAAC}_{6}$ ligands. The ability of CAAC ligands to control regioselectivity in $\mathrm{LCu}\left(\mathrm{BX}_{2}\right)$ additions to $\pi$-bonds has significant implications given the wide array of electrophilic reaction partners that participate in this mode of catalysis ${ }^{33}$ and its demonstrated use as a constituent component of powerful dual catalytic processes. ${ }^{34}$

1 (a) Miyaura, N.; Suzuki, A. Palladium-Catalyzed Cross-Coupling Reactions of Organoboron Compounds. Chem. Rev. 1995, 95, 2457-2483. (b) Moran W. J.; Morken, J. P. Rh-Catalyzed Enantioselective Hydrogenation of Vinyl Boronates for the Construction of Secondary Boronic Esters. Org. Lett. 2006, 8, 2413-2415. (c) Molander, G. A.; Ellis, N. Organotrifluoroborates: Protected Boronic Acids That Expand the Versatility of the Suzuki Coupling Reaction. Acc. Chem. Res. 2007, 40, 275286. (d) Tobisu, M.; Chatani, N. Devising Boron Reagents for Orthogonal Functionalization through Suzuki-Miyaura Cross-Coupling. Angew. Chem., Int. Ed. 2009, 48, 3565-3568. (e) Lennox, A. J.; LloydJones, G. C. Selection of Boron Reagents for Suzuki-Miyaura Coupling. Chem. Soc. Rev. 2014, 43, 412-443. (f) Zhang, L.; Lovinger, G. J.; Edelstein, E. K..; Szymaniak, A. A.; Chierchia, M. P.; Morken, J. P. Catalytic Conjunctive Cross-Coupling Enabled by Metal-Induced Metallate Rearrangement. Science 2016, 351, 70-74. (g) Ueda, M.; Kato, Y.; Taniguchi, N.; Morisaki, T. High Reactivity of $\alpha$-Boryl Radical of Potassium Aklyltrifluoroborate in Atom-Transfer Radical Addition. Org.

\section{AUTHOR INFORMATION}

\section{Corresponding Author}

keary@scripps.edu

rjazzar@ucsd.edu

guybertrand@ucsd.edu

\section{Author Contributions}

$\$$ These authors contributed equally.

\section{ORCID}

Yang Gao: 0000-0001-9270-6251

Sima Yazdani: 0000-0003-0261-7146

Glen P. Junor: 0000-0002-6733-3577

Douglas B. Grotjahn 0000-0002-2481-7889

Guy Bertrand: 0000-0003-2623-2363

Rodolphe Jazzar: 0000-0002-4156-7826

Keary Engle: 0000-0003-2767-6556

\section{Funding Sources}

The authors declare no financial competing interests.

\section{ACKNOWLEDGMENT}

This work was financially supported by the National Institute of Health (5R35GM125052-04 and diversity supplement, 5R35GM125052-04S1) and an ACS PRF Doctoral New Investigator Grant (K.M.E.). This work was also supported by the U.S. Department of Energy, Office of Science, Basic Energy Sciences, Catalysis Science Program, under Award No. DE-SC0009376 (G.B.), National Science Foundation Award No. CHE-1800598 (D.B.G.) and the Agence Nationale de la Recherche Award No. ANR-19-276 CE07-0017 (R.J). Thanks are due to San Diego State University for initial support of this work by a SDSU University Graduate Fellowship (S.Y.) and the Alfred P. Sloan Foundations University Centre for Exemplary Mentoring (G.P.J.). This material is based upon work supported by the National Science Foundation Graduate Research Fellowship Program under Grant No. DGE-1650112 (G.P.J.). We also acknowledge the Keck Foundation for provided computational resources.

\section{REFERENCE}

Lett. 2020, 22, 6234-6238. (h) Grygorenko, O. O.; Moskvina, V. S.; Hryshchuk, O. V.; Tymtsunik, A. V. Cycloaddition of Alkenylboronic Derivatives. Synthesis 2020, 52, 2761-2780.

2 Beletskaya, I.; Pelter, A. Hydroborations Catalysed by Transition Metal Complexes. Tetrahedron 1996, 53, 4957-5026.

3 For selected recent publications on metal-catalyzed anti-Markovnikov hydroborylation of terminal alkynes, see: (a) Pereira, S.; Srebnik, M. A Study of Hydroboration of Alkenes and Alkynes with pinacolborane Catalyzed by Transition Metals. Tetrahedron Lett. 1996, 37, 32833286. (b) Wang, Y. D.; Kimball, G.; Prashad, A. S.; Wang, Y. Zr-Mediated Hydroboration: Stereoselective Synthesis of Vinyl Boronic Esters. Tetrahedron Lett. 2005, 46, 8777-8780. (c) Iwadate, N.; Suginome, M. Synthesis of B-Protected $\beta$-Styrylboronic Acids via Iridium-Catalyzed Hydroboration of Alkynes with 1,8-Naphthalenediaminatoborane 
Leading to Iterative Synthesis of Oligo(phenylenevinylene)s. Org. Lett. 2009, 11, 1899-1902 (d) Jang, W. J.; Lee, W. L.; Moon, J. H.; Lee, J. Y.; Yun, J. Copper-Catalyzed trans-Hydroboration of Terminal Aryl Alkynes: Stereodivergent Synthesis of Alkenylboron Compounds. Org. Lett. 2016, 18, 1390-1393. (e) Wang, Y.; Guan, R.; Sivaguru, P.; Cong, $\mathrm{X}$.; Bi, X. Silver-Catalyzed anti-Markovnikov Hydroboration of C-C Multiple Bonds. Org. Lett. 2019, 21, 4035-4038.

4 (a) Jang, H.; Zhugralin, A. R.; Lee, Y.; Hoveyda, A. H. Highly Selective Methods for Synthesis of Internal ( $\alpha$-) Vinylboronates through Efficient NHC-Cu-Catalyzed Hydroboration of Terminal Alkynes. Utility in Chemical Synthesis and Mechanistic Basis for Selectivity. J. Am. Chem. Soc. 2011, 133, 7859-7871. (b) Moure, A. L.; Mauleón, P.; Arrayás, R. G.; Carretero, J. C. Formal Regiocontrolled Hydroboration of Unbiased Internal Alkynes via Borylation/Allylic Alkylation of Terminal Alkynes. Org. Lett. 2013, 15, 2054-2057. (c) Yoshida, H.; Takemoto, Y.; Takaki, K. A Masked Diboron in Cu-Catalysed Borylation Reaction: Highly Regioselective Formal Hydroboration of Alkynes for Synthesis of Branched Alkenylborons. Chem. Commun. 2014, 50, 8299-8302. (d) Ojha, D. P.; Prabhu, K. R. Pd-Catalyzed Hydroborylation of Alkynes: A Ligand Controlled Regioselectivity Switch for the Synthesis of $\alpha$ - or $\beta$-Vinylboronates. Org. Lett. 2016, 18, 432-435. (e) Zhang, P.; Suárez, J. M.; Driant, T.; Derat, E.; Zhang, Y.; Ménand, M.; Roland, S.; Sollogoub, M. Cyclodextrin Cavity-Induced Mechanistic Switch in Copper-Catalyzed Hydroboration. Angew. Chem. Int. Ed. 2017, 56, 10821-10825. (f) Chen, J.; Shen, X.; Lu, Z. Cobalt-Catalyzed Markovnikov-Type Selective Hydroboration of Terminal Alkynes. Angew. Chem. Int. Ed. 2021, 60, 690-694.

5 Lavallo, V.; Canac, Y. ; Prasang, C. ; Donnadieu, B. ; Bertrand, G. Stable Cyclic (Alkyl)(Amino)Carbenes as Rigid or Flexible, Bulky, ElectronRich Ligands for Transition Metal Catalysts: A Quaternary Carbon Makes the Difference. Angew. Chem. Int. Ed. 2005, 44, 5705-5709

6 Weinstein, C. M.; Junor, G. P.; Tolentino, D. R.; Jazzar, R.; Melaimi, M.; Bertrand, G. Highly Ambiphilic Room Temperature Stable Six-Membered Cyclic (Alkyl) (amino)carbenes. J. Am. Chem. Soc. 2018, 140, 9255-9260.

7 Tomás-Mendivil, E.; Hansmann, M. M.; Weinstein, C. M.; Jazzar, R.; Melaimi, M.; Bertrand, G. Bicyclic (Alkyl)(amino)carbenes (BICAACs): Stable Carbenes More Ambiphilic than CAACs. J. Am. Chem. Soc. 2017, 139, 7753-7756.

8 Chu, J.; Munz, D.; Jazzar, R.; Melaimi, M.; Bertrand, G. Synthesis of Hemilabile Cyclic (Alkyl) (amino)carbenes (CAACs) and Applications in Organometallic Chemistry. J. Am. Chem. Soc. 2016, 138, 78847887.

9 Pichon, D.; Soleilhavoup, M.; Morvan, J.; Junor, G. P.; Vives, T.; Crévisy, C.; Lavallo, V.; Campagne, J.-M.; Mauduit, M.; Jazzar, R.; Bertrand, G. The Debut of Cyclic (Alkyl)(Amino)Carbenes (CAACs) in Enantioselective Catalysis. Chem. Sci. 2019, 10, 7807-7811.

10 For reviews on applications of CAACs-ligated metal complexes in catalysis, see: (a) Jazzar, R.; Soleilhavoup, M.; Bertrand, G. Cyclic (Alkyl)and (Aryl)-(amino)carbene Coinage Metal Complexes and Their Applications. Chem. Rev. 2020, 120, 4141-4168. (b) Morvan, J.; Mauduit, M.; Bertrand, G.; Jazzar, R. Cyclic (Alkyl) (amino)carbenes (CAACs) in Ruthenium Olefin Metathesis. ACS Catal. 2021, 11, 1714-1748. For other innovative applications, see: (c) Melaimi, M.; Jazzar, R.; Soleilhavoup M.; Bertrand, G. Cyclic (Alkyl)(amino)carbenes (CAACs): Recent Developments. Angew. Chem. Int. Ed. 2017, 56, 10046-10068.

11 For reviews on electronic properties of CAAC carbenes, see: (a) Melaimi, M.; Soleilhavoup, M.; Bertrand, G. Stable Cyclic Carbenes and Related Species beyond Diaminocarbenes. Angew. Chem. Int. Ed. 2010, 49, 8810-8849. (b) Soleilhavoup, M.; Bertrand, G. Cyclic (Alkyl)(Amino)Carbenes (CAACs): Stable Carbenes on the Rise. Acc. Chem. Res. 2015, 48, 256-266. (c) Paul, U. S. D.; Radius, U. What Wanzlick Did Not Dare to Dream: Cyclic (Alkyl)(amino)carbenes (CAACs) as New Key Players in Transition-Metal Chemistry. Eur. J. Inorg. Chem. 2017, 3362-3375.

12 For reviews on NHC carbenes, see: (a) Hopkinson, M. N.; Richter, C.; Schedler, M.; Glorius, F. An Overview of N-Heterocyclic Carbenes. Nature 2014, 510, 485-496. (b) Gonzalez, S. D.; Marion, N.; Nolan, S. P. $\mathrm{N}-\mathrm{Heterocyclic} \mathrm{Carbenes} \mathrm{in} \mathrm{Late} \mathrm{Transition} \mathrm{Metal} \mathrm{Catalysis.} \mathrm{Chem.}$
Rev. 2009, 109, 3612-3676. For a recent book on NHCs, see: DíezGonzález, S. N-Heterocyclic Carbenes: From Laboratory Curiosities to Efficient Synthetic Tools, Royal Society of Chemistry: Cambridge, 2016.

13 For a summary of pinB-SiMe $2 \mathrm{Ph}$ chemistry, see: Ohmura, T.; Suginome, M. Silylboranes as New Tools in Organic Synthesis. Bull. Chem. Soc.Jpn. 2009, 82, 29-49)

14 Meng, F.; Jang, H.; Hoveyda, A. H. Exceptionally $E$ - and $\beta$-Selective NHC-Cu-Catalyzed Proto-Silyl Additions to Terminal Alkynes and Site- and Enantioselective Proto-Boryl Additions to the Resulting Vinylsilanes: Synthesis of Enantiomerically Enriched Vicinal and Geminal Borosilanes. Chem. Eur.J. 2013, 19, 3204-3214.

15 Molander, G. A.; McKee, S. A. Copper-Catalyzed $\beta$-Boration of $\alpha, \beta$-Unsaturated Carbonyl Compounds with Tetrahydroxydiborane. Org. Lett. 2011, 13, 4684-4687. We observed that in this particular case, reactions using SIPr or SIMes as ligand gave the same $\alpha: \beta$ ratios, suggesting that the regioselectivity is controlled by the $\mathrm{B}_{2}(\mathrm{OH})_{4}$ reagent.

16 You, C.; Studer, A. Synthesis of 1,3-Bis-(boryl)alkanes through Boronic Ester Induced Consecutive Double 1,2-Migration. Angew. Chem. Int. Ed. 2020, 59, 17245-17249.

17 Lo, J. C.; Kim, D.; Pan, C.-M.; Edwards, J. T.; Yabe, Y.; Gui, J.; Qin, T.; Gutiérrez, S.; Giacoboni, J.; Smith, M. W.; Holland, P. L.; Baran, P. S. Fe-Catalyzed C-C Bond Construction from Olefins via Radicals. J. Am. Chem. Soc. 2017, 139, 2484-2503.

18 Uno, B. E.; Gillis, E. P.; Burke, M. D. Vinyl MIDA Boronate: A Readily Accessible and Highly Versatile Building Block for Small Molecule Synthesis. Tetrahedron 2009, 65, 3130-3138.

19 Wilkinson, J. R.; Nuyen, C. E.; Carpenter, T. S.; Harruff, S. R.; Van Hoveln, R. Copper-Catalyzed Carbon-Silicon Bond Formation. ACS Catalysis 2019, 9, 8961-8979.

20 Wang, P.; Yeo, X.-L.; Loh, T.-P. Copper-Catalyzed Highly Regioselective Silylcupration of Terminal Alkynes to Form $\alpha$-Vinylsilanes. J. Am. Chem. Soc. 2011, 133, 1254-1256.

21 Unfortunately, we are unable make direct head-to-head comparisons with the examples in Table 3 to pin down the influence of the migrating group since the ligand is different in the two systems.

22 All computational results are available for download free of charge from UCSD Library Digital Collections. Gao, Y.; Yazdani, S.; Kendrick, A. IV; Junor, G. P.; Grotjahn, D. B.; Bertrand, G.; Jazzar, R.; Engle, K. M. Data from: Cyclic(Alkyl)(Amino)Carbene Ligands Enable Cu-Catalyzed Markovnikov Protoboration and Protosilylation of Terminal Alkynes: A Versatile Portal to Functionalized Alkenes; UC San Diego Library Digital Collections: Dataset (2021) DOI: 10.6075/J00P0XK4.

23 (a) Falivene, L.; Credendino, R.; Poater, A.; Petta, A.; Serra, L.; Oliva, R.; Scarano, V.; Cavallo, L. SambVca 2. A Web Tool for Analyzing Catalytic Pockets with Topographic Steric Maps. Organometallics 2016, 35, 2286-2293. (b) Falivene, L.; Cao, Z.; Petta, A.; Serra, L.; Poater, A.; Oliva, R.; Scarano, V.; Cavallo, L. Towards the Online Computer-Aided Design of Catalytic Pockets. Nat. Chem. 2019, 11, 872-879.

24 Clavier, H.; Nolan, S. P. Percent buried volume for phosphine and Nheterocyclic carbene ligands: steric properties in organometallic chemistry. Chem. Comm. 2010, 46, 841-861.

25 (a) Junor, G. P.; Lorkowski, J.; Weinstein, C. M.; Jazzar, R.; Pietraszuk, C.; Bertrand G. The influence of $\mathrm{C}(\mathrm{sp} 3) \mathrm{H}$-Selenium Interactions on the ${ }^{77} \mathrm{Se}$ NMR Quantification of the $\pi$-Accepting Properties of Carbenes. Angew. Chem. Int. Ed. 2020, 59, 22028-22033.

26 Yazdani, S.; Junor, G. P.; Peltier, J. L.; Gembicky, M.; Jazzar, R.; Grotjahn, D. B.; Bertrand, G. ACS Catal. 2020, 10, 5190-5201.

27 (a) Huynh, H. V. Electronic Properties of N-Heterocyclic Carbenes and Their Experimental Determination. Chem. Rev. 2018, 118, 9457-9492. (b) Nelson, D. J.; Nolan, S. P. Quantifying and Understanding the Electronic Properties of $\mathrm{N}$-Heterocyclic Carbenes. Chem. Soc. Rev. 2013, 42, 6723-6753.

28 Dorta, R.; Stevens, E. D.; Scott, N. M.; Costabile, C.; Cavallo, L.; Hoff, C. D.; Nolan, S. P. Steric and Electronic Properties of N-Heterocyclic Carbenes (NHC): A Detailed Study on Their Interaction with $\mathrm{Ni}(\mathrm{CO})_{4}$. J. Am. Chem. Soc. 2005, 127, 2485-2495. 
29 Hansch, C.; Leo, A.; Taft, R. W. A Survey of Hammett Substituent Constants and Resonance and Field Parameters. Chem. Rev. 1991, 91, 165195.

30 Lee, K.-S.; Hoveyda, A. H. Enantioselective Conjugate Silyl Additions to Cyclic and Acyclic Unsaturated Carbonyls Catalyzed by $\mathrm{Cu} \mathrm{Com}-$ plexes of Chiral N-Heterocyclic Carbenes. J. Am. Chem. Soc. 2010, 132, 2898-2900.

31 Laitar, D. S.; Müller, P.; Sadighi, J. P. Efficient Homogeneous Catalysis in the Reduction of $\mathrm{CO}_{2}$ to CO.J. Am. Chem. Soc. 2005, 127, 17196 17197.

32 (a) Plotzitzka, J.; Kleeberg, C. [(NHC)CuI-ER $]$ Complexes $\left(\mathrm{ER}_{3}=\right.$ $\mathrm{SiMe}_{2} \mathrm{Ph}, \mathrm{SiPh}_{3}, \mathrm{SnMe}_{3}$ ): From Linear, Mononuclear Complexes to Polynuclear Complexes with Ultrashort CuI...CuI Distances. Inorg. Chem. 2016, 55, 4813-4823. (b) Kleeberg, C.; Cheung, M. S.; Lin, Z.; Marder, T. B. Copper-Mediated Reduction of $\mathrm{CO}_{2}$ with pinB-SiMe ${ }_{2} \mathrm{Ph}$ via $\mathrm{CO}_{2}$ Insertion into a Copper-Silicon Bond. J. Am. Chem. Soc. 2011, 133, 19060-19063. (c) McCarty, B. J.; Thomas, B. M.; Zeller, M.; Hoveln, R. V. Synthesis of a Copper Silyl Complex by Disilane Activation. Organometallics 2018, 37, 2937-2940.

33 For reviews on $\mathrm{Cu}$-catalyzed protoboration and borylative difunctionalization of $\pi$-system, see: (a) Yun, J. Copper(I)-Catalyzed Boron Addition Reactions of Alkynes with Diboron Reagents. Asian J. Org. Chem. 2013, 2, 1016-1025. (b) Semba, K.; Fujihara, T.; Terao, J.; Tsuji, Y. Copper-Catalyzed Borylative Transformations of Non-Polar CarbonCarbon Unsaturated Compounds Employing Borylcopper as An Active Catalyst Species. Tetrahedron 2015, 71, 2183-2197. (c) Yoshida, H. Borylation of Alkynes under Base/Coinage Metal Catalysis: Some Recent Developments. ACS Catal. 2016, 6, 1799-1811. (d) Hemming, D.; Fritzemeier, R.; Westcott, S. A.; Santos, W. L.; Steel, P. G. Copper-
Boryl Mediated Organic Synthesis. Chem. Soc. Rev. 2018, 47, $7477-$ 7494. (e) Whyte, A.; Torelli, A.; Mirabi, B.; Zhang, A.; Lautens, M. Copper-Catalyzed Borylative Difunctionalization of $\pi$-Systems. ACS Catal. 2020, 10, 11578-11622.

34 For selected recent publications on cooperative $\mathrm{Pd} / \mathrm{Cu}$ or $\mathrm{Ni} / \mathrm{Cu}$ catalysis for difunctionalization of $\pi$-system, see: (a) Semba, K.; Nakao, Y. Arylboration of Alkenes by Cooperative Palladium/Copper Catalysis. J. Am. Chem. Soc. 2014, 136, 7567-7570. (b) Logan, K. M.; Smith, K. B.; Brown, M. K. Copper/Palladium Synergistic Catalysis for the synand anti-Selective Carboboration of Alkenes. Angew. Chem. Int. Ed. 2015, 54, 5228-5231. (c) Semba, K.; Ohtagaki, Y.; Nakao, Y. Arylboration of 1-Arylalkenes by Cooperative Nickel/Copper Catalysis. Org. Lett. 2016, 18, 3956-3959. (d) Sardini, S. R.; Brown, M. K. Catalyst Controlled Regiodivergent Arylboration of Dienes. J. Am. Chem. Soc. 2017, 139, 9823-9826. (e) Semba, K.; Ohta, N.; Yano, Y.; Nakao, Y. Carboallylation of Electron-Deficient Alkenes by Palladium/Copper Catalysis. Chem. Commun. 2018, 54, 11463-11466. (f) Bergmann, A.; Dorn, S.; Smith, K. B.; Logan, K.; Brown, M. K. Catalyst-Controlled 1,2and 1,1-Arylboration of a-Alkyl Alkenylarenes. Angew. Chem. Int. Ed. 2019, 58, 1719-1723. (g) Huang, Y.; Brown, M. K. Synthesis of Bisheteroarylalkenes by Heteroarylboration: Development and Application of a Pyridylidene-Cu Complex. Angew. Chem. Int. Ed. 2019, 58, 60486052. (h) Semba, K.; Ohta, N.; Nakao, Y. Carboallylation of ElectronDeficient Alkenes with Organoboron Compounds and Allylic Carbonates by Cooperative Palladium/Copper Catalysis. Org. Lett. 2019, 21,4407-4410. (i) Bergmann, A. M.; Sardini, S. R.; Smith, K. B.; Brown, M. K. Regioselective Arylboration of 1,3-Butadiene. Isr. J. Chem. 2020, 60, 394-397. 